\title{
Spatial Distribution of Urban Air Pollution in Lanzhou, China
}

\author{
Francesca Costabile, Giuliano Bertoni*, Franco De Santis, Raffaella Bellagotti, Carla Ciuchini, \\ Francesca Vichi and Ivo Allegrini
}

CNR-IIA, Via Salaria km 29,300, Monterotondo - Rome, Italy

\begin{abstract}
Urban air quality, and its variability in space and time, is a critical issue for human exposure and health related studies. In this work, we investigated the intra-urban distribution of $\mathrm{SO}_{2}, \mathrm{NO}_{\mathrm{x}}, \mathrm{NO}_{2}$, Benzene, Toluene, and Xylenes in ambient air in one of the world's most polluted cities, Lanzhou, China. Measurements were contemporarily carried out at forty locations in four seasonal campaigns during the period 2005-2006. Diffusive samplers allowing a sampling period of one month were used. As a general finding, the selected air pollutant concentrations often exceeded the EU limit values, and varied significantly with space, time, and proximity to relevant point emission sources. A statistical analysis revealed that monthly air pollutant concentrations were normally distributed in space. This suggests that the spatial distribution of urban air pollution was governed by the spatial diffusion of emission sources, at least for its apparent average behaviour. This result might be relevant to link urban air quality measurements and human exposure assessment. To gain insights into the properties of the urban air pollution distribution in space, makes the assessment of homogeneous areas of air pollution in the urban area less critical - and, consequently, allows a proper selection of the sites where to monitor air quality for health-effects studies.
\end{abstract}

Keywords: Spatial distribution, frequency distributions, gaseous air pollutants, China, diffusive sampling.

\section{INTRODUCTION}

Urban air quality is of considerable interest in both developed and developing Countries, such as China. In particular, the variability in space and time of urban air pollutants is a critical issue for exposure and health related studies. In fact, there is a growing evidence for associations between exposure and human health, and an increasing requirement for action to control and reduce levels of air pollution.

In the past, most epidemiological studies had used available ambient air monitoring data as surrogate for the exposure of the population of interest [1]. Exposure had often been characterised with one city average concentration only, by using the air pollution data from a single monitoring site or the average of observations from a few monitoring sites to represent the whole population of the study area [2]. A common assumption was that certain pollutants were homogeneously distributed in space within a large urban area.

Some epidemiological studies have recently shown the importance of accounting for within-city variability in air pollution concentrations $[3,4]$. This variability often results in inconsistent comparisons for air quality data among different sites, and, consequently, inconsistent actions to control air quality and to assess people exposure. A better understanding of the "representativeness" of air quality measurements with respect to exposure assessment is therefore important [5-7] In this study we investigated the urban air pollution distribution in Lanzhou, China. Lanzhou, in the Gansu province, is about $1,800 \mathrm{~km} \mathrm{SW}$ of Beijing, with a popula

*Address correspondence to this author at the CNR-IIA, Via Salaria $\mathrm{km}$ 29,300, Monterotondo - Rome, Italy; Tel: +3906 90672272; Fax: +3906 90672661; E-mail: bertoni@iia.cnr.it tion of about 3 million inhabitants. Due of its special geographical location and of a large amount of emissions from coal-fired factories [8-11], Lanzhou is one of the most seriously polluted cities in the world. The city is situated in a valley along the course of an important river and between two high mountain ranges (cf. Fig. (1)). As reported by Wang [12] the air pollution problem in Lanzhou is well known since the late 1970s, when a serious photochemical event was noticed for the first time in China.

In the years 2005-2006, we measured $\mathrm{SO}_{2}, \mathrm{NO}_{2}, \mathrm{NO}_{\mathrm{x}}$, Benzene, Toluene and Xylene (BTX) in the ambient air of Lanzhou, at 40 measurement sites during four seasonal campaigns. Our aim was to investigate both pollutant concentrations, and the possibility to describe by a simple statistical model their spatial distribution.

\section{METHODS}

Almost 800 samplers of $\mathrm{SO}_{2}, \mathrm{NO}_{\mathrm{x}}, \mathrm{NO}_{2}$ and $\mathrm{BTX}$ were taken for this work by using the Analyst diffusive samplers (Marbaglass, Rome, Italy). The development of this sampler, the theory, the use and comparison with automatic reference methods and the protocol to select the micro-scale locations of each site were described in previous publications $[5,13$ 15]. Measurements were taken in four representative periods of an entire year at 40 locations (Fig. 1). The inter-distances between the measurement locations spanned from $1 \mathrm{~km}$ (minimum distance, between e.g. sites 4 and 5) to $30 \mathrm{~km}$ (maximum distance between e.g. sites 2 and 34). The locations were fitted as much as possible over a geometric grid. The number of sites (40) reflected a compromise between a good spatial coverage, and a bearable experimental cost. In this case, costs were further lowered due to the suitability of the Analyst device to work with a linear sampling rate over a 


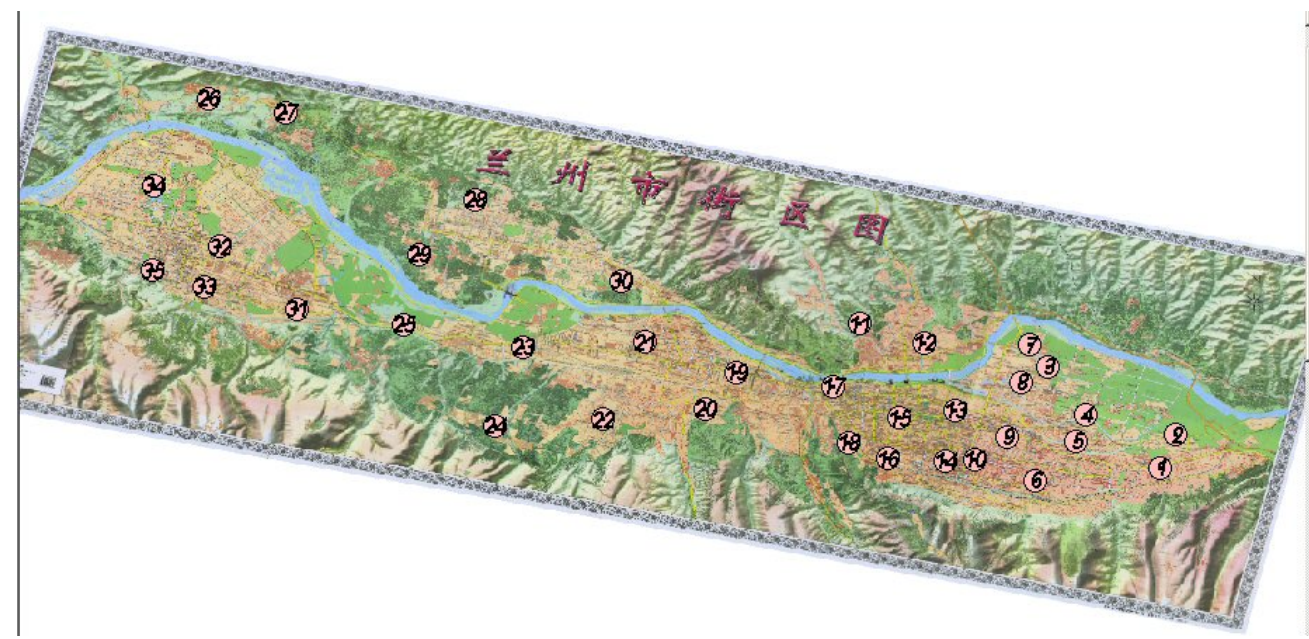

Fig. (1). Schematic representation of the sampling sites in Lanzhou. The maximum distance between the measurement site is about $30 \mathrm{~km}$; the minimum distance is $1 \mathrm{~km}$.

Table 1. Classification of Sampling Sites in Terms of Emission Sources. A=Urban Background; B=Residential Area; Bind=Industrial Areas; $C=$ Traffic Zone; $D=$ Regional Background

\begin{tabular}{|c|c|c|c|c|c|c|c|c|c|c|}
\hline SITE & L1 & L2 & L3 & L4 & L5 & L6 & L7 & L8 & L9 & L10 \\
\hline \hline $\begin{array}{c}\text { MAIN } \\
\text { TYPE }\end{array}$ & C & B/Bind & B & C/Bind & B & B & B & B/C & B & B \\
\hline SITE & L11 & L12 & L13 & L14 & L15 & L16 & L17 & L18 & L19 & L20 \\
\hline $\begin{array}{c}\text { MAIN } \\
\text { TYPE }\end{array}$ & A & B & B & B & B & B & B & B & C \\
\hline SITE & L21 & L22 & L23 & L24 & L25 & L26 & L27 & L28 & L29 & L30 \\
\hline $\begin{array}{c}\text { MAIN } \\
\text { TYPE }\end{array}$ & Bind/C & B & Bind & A & B & A/Bind & A/Bind & A & Bind/A & B \\
\hline SITE & L31 & L32 & L33 & L34 & L35 & L36 & L37 & L38 & L39 & L40 \\
\hline $\begin{array}{l}\text { MAIN } \\
\text { TYPE }\end{array}$ & C/Bind & Bind & B/C & Bind & B & D & D & D & D \\
\hline
\end{tabular}

long period (one month). This allowed us to investigate the average concentration values along monthly periods, with a reduced number of devices - and analyses - required to cover both a large territorial area and a long period. Moreover, this method allowed also to extend our studies to obtain helpful results about the seasonal variability. Point emission sources close to every single location were inventoried, and accordingly the measurement sites were classified as representative of 1) regional, 2) urban background pollution, 3) populationexposure and traffic and 4) industrial emissions (Table 1). The four seasonal campaigns were carried out in autumn (October $15^{\text {th }}-$ November $15^{\text {th }}, 2005$ ), winter (January $15^{\text {th }}$ February $15^{\text {th }}, 2006$ ), spring (April $15^{\text {th }}-$ May $15^{\text {th }}, 2006$ ), and summer (July $15^{\text {th }}$-August $15^{\text {th }}, 2006$ ). In addition, as the main part of a QA/QC program, duplicated samplers covering twenty percent of the total sites were collected. Thanks to the large number of measurements it was possible to collect a significant statistical sample of data. The data-set was statistically analysed along the space coordinates. The data-set comprised between the maximum and minimum values was tested for statistical normality of the frequency distribution (FD) in order to evaluate the statistical model describing it. The outliers values were calculated according to Eq.1 [16]:

$$
\text { Outlier }=\left\{\begin{array}{l}
>75_{t h}+1.5 \cdot I Q \\
<25 t h-1.5 \cdot I Q
\end{array}\right.
$$

where IQ indicates the interquartile range, that is: IQ $=75^{\text {th }}$ percentile- $25^{\text {th }}$ percentile, and subtracted by the data-set. This selection avoids local or feeble events to influence the final data-base. Data normality was investigated according to a methodology previously adopted by the authors [15]. In short, the Kolmogorov-Smirnov (K-S) test was used. According to this test (cf. Table 2), K-S distance represents the maximum cumulative distance between the histogram of measured data and the Gaussian distribution curve of data. The Probability $(\mathrm{P})$ value is the probability that the population of data measured is normally distributed - if the P computed by the test is greater than an acceptable level of significance (set to 0.05 ), the data can be considered normal. 
Table 2. Results of the Normality Test for the Total Data Without Outlier. The Table Shows the Pollutant Investigated, the Field Campaign, and the Results of the Kolmogorov-Smirnov Test for Data Normality. Kolmogorov-Smirnov (K-S) Distance = Maximum Cumulative Distance Between the Histogram of Measured Data and the Gaussian Distribution Curve of Data. P: Probability Value that the Population of Data Measured is Normally Distributed. (P>0.05 is the Acceptable Probability, Assuming no Significant Discrepancy At the $5 \%$ Significance Level Between the Estimated and Measured Distributions of Pollutants)

\begin{tabular}{|c|c|c|c|c|}
\hline Pollutant & Campaign ID & \multicolumn{3}{|c|}{ Kolmogorov-Smirnov Test for Normal Distribution } \\
\hline \multirow{2}{*}{ Benzene } & II & 0.099 & $>0.200$ & Passed \\
\hline & III & 0.152 & $=0.046$ & Failed \\
\hline \multirow{4}{*}{ Toluene } & I & 0.071 & $>0.200$ & Passed \\
\hline & II & 0.132 & $=0.120$ & Passed \\
\hline & III & 0.089 & $>0.200$ & Passed \\
\hline & IV & 0.118 & $>0.200$ & Passed \\
\hline \multirow{2}{*}{ Xylenes } & III & 0.085 & $>0.200$ & Passed \\
\hline & IV & 0.088 & $>0.200$ & Passed \\
\hline \multirow{4}{*}{$\mathrm{SO}_{2}$} & I & 0.115 & $>0.200$ & Passed \\
\hline & II & 0.078 & $>0.200$ & Passed \\
\hline & III & 0.079 & $>0.200$ & Passed \\
\hline & IV & 0.114 & $>0.200$ & Passed \\
\hline $\mathrm{NO}_{\mathrm{x}}$ & I & 0.100 & $>0.200$ & Passed \\
\hline \multirow{2}{*}{$\mathrm{NO}_{2}$} & III & 0.088 & $>0.200$ & Passed \\
\hline & IV & 0.083 & $>0.200$ & Passed \\
\hline
\end{tabular}

\section{RESULTS AND DISCUSSION}

\subsection{Urban Air Pollution Variability}

Figure 2 shows the results of the measurements taken at the 40 sampling locations, for all selected pollutants, and during the four seasonal campaigns.

All measured pollutants show a common seasonal variability with lower values in summer and significant differences between the colder and the warmer seasons. $\mathrm{SO}_{2}$ and $\mathrm{NO}_{2}$ concentrations were compared (Fig. 3) to the correspondent average values measured during the previous 5 years by automatic analysers at two locations (site number
12 and 32, Fig. 1) [17]. (No data were available for the other pollutants). No obvious changes in the seasonal trend can be recognised since the year 2000, in accordance with other recent papers $[8,18]$. Benzene values were lower than 5 $\mu \mathrm{g} / \mathrm{m}^{3}$ (limit value set by European Union, to be attained by the year 2010) only in summer - they peaked in autumn over $10 \mu \mathrm{g} / \mathrm{m}^{3}$. All the BTX outliers were measured at industrial and traffic sites (Fig. 2). Similarly, Xylenes values were on average $4-5 \mu \mathrm{g} / \mathrm{m}^{3}$, with the exception of autumn when the concentrations were almost doubled, as discussed below. Toluene averaged around $15 \mu \mathrm{g} / \mathrm{m}^{3}$, with higher winter and lower summer levels similar to the inorganic pollutants, $\mathrm{SO}_{2}$ and $\mathrm{NO}_{2}$, whose yearly average concentrations - estimated 

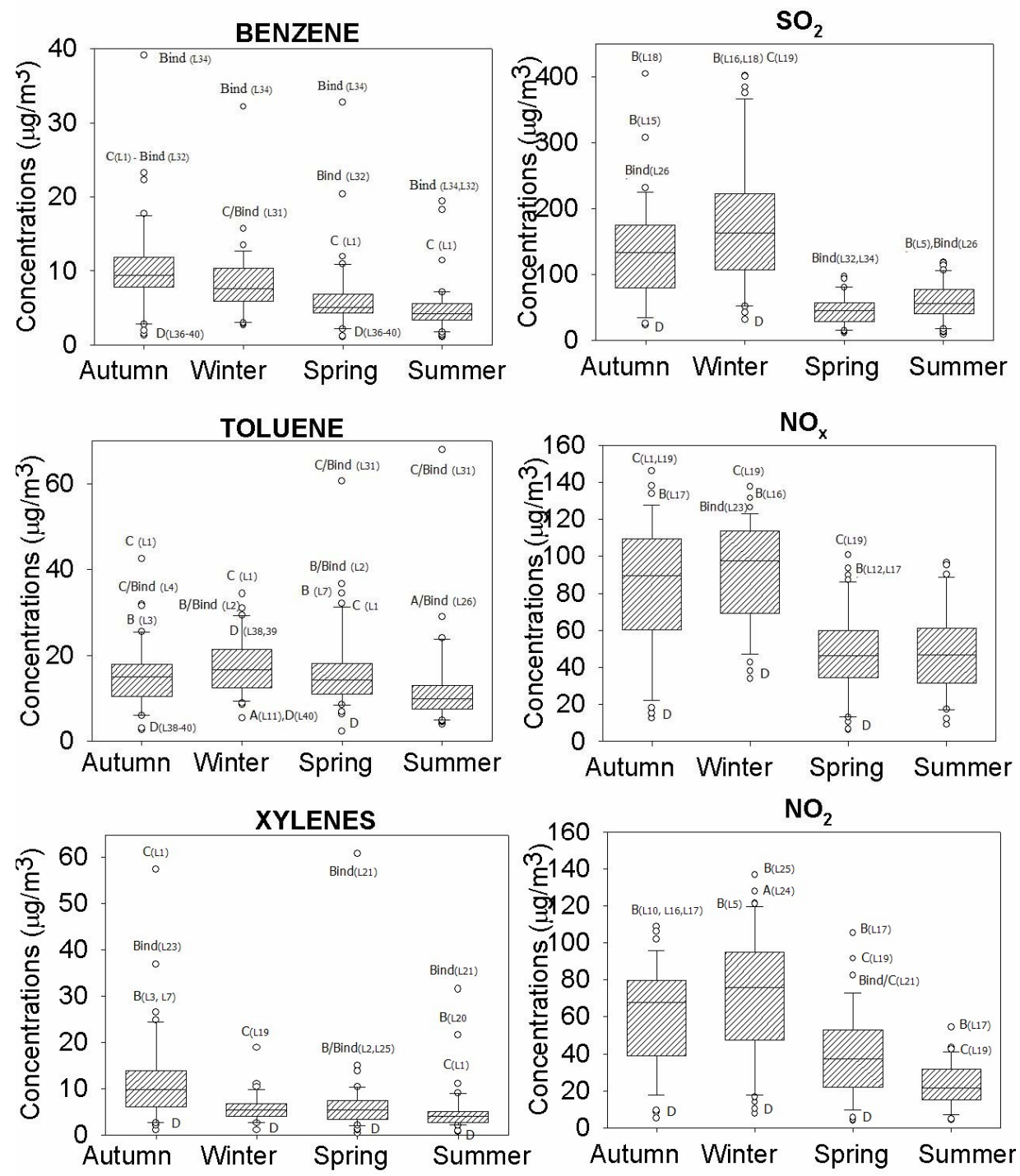

Fig. (2). Box-plot of pollutant concentrations calculated among the 40 sites. Upper and lower dots indicates the outliers (for the classification of these outliers, see caption of Table 1). Filled boxes indicates interquartile and horizontal lines show the max and min values.

by using the 4 monitoring periods - almost exceeded the EU limit value of $20 \mu \mathrm{g} / \mathrm{m}^{3}$ and of the limit value added of the margin of tolerance (for the year 2006) of $50 \mu \mathrm{g} / \mathrm{m}^{3}$, respectively [19]. Hot spots for sulphur dioxide were found mainly at residential sites in colder seasons (coal burning) and industrial sites in warmer periods (Fig. 2). The observed seasonal trends for $\mathrm{NO}_{\mathrm{x}}$ are similar to those of $\mathrm{NO}_{2}$. However, differences were found in summer (Fig. 2), most likely because of higher temperatures and insulation rates. (The partitioning of $\mathrm{NO}_{\mathrm{x}}$ between $\mathrm{NO}$ and $\mathrm{NO}_{2}$ is a convenient variable of the extent and completeness of atmospheric oxidation processes). Moreover, the outliers were found only for $\mathrm{NO}_{\mathrm{x}}$ at the traffic sites (Fig. 2).

Seasonal variations are primarily dependent on emission patterns, meteorology and photochemistry. The higher winter values were probably due to the burning of coal for heating in Lanzhou [20]; on the contrary, traffic and industrial process emissions are expected to remain reasonably constant throughout the year. Besides, Lanzhou Municipality has a complete spectrum of light and heavy industries: petroleum, chemical industry, mechanics and metallurgy, and also textile, food, medicine, electricity, cement, steel and iron, nonferrous metal, coal and building materials [17]. Some of these industries emit great amounts of gaseous pollutants, with significant time variations during the year. The Lanzhou semi-arid continental monsoon climate can explain these seasonal variations. There is little precipitation - sixty percent of this precipitation is concentrated in the summer months of July, August and September [17]. There also is a significant temperature difference between winter and summer, and the yearly average temperature in the middle river valley area (between $8{ }^{\circ} \mathrm{C}$ and $9^{\circ} \mathrm{C}$ ) is higher than the average in the close mountainous areas (between $2{ }^{\circ} \mathrm{C}$ and $5{ }^{\circ} \mathrm{C}$ ). In fact, because of the particular Lanzhou's topography, there are very often long-term inversions trapping pollutants at the ground level, especially during the winter season [9, 


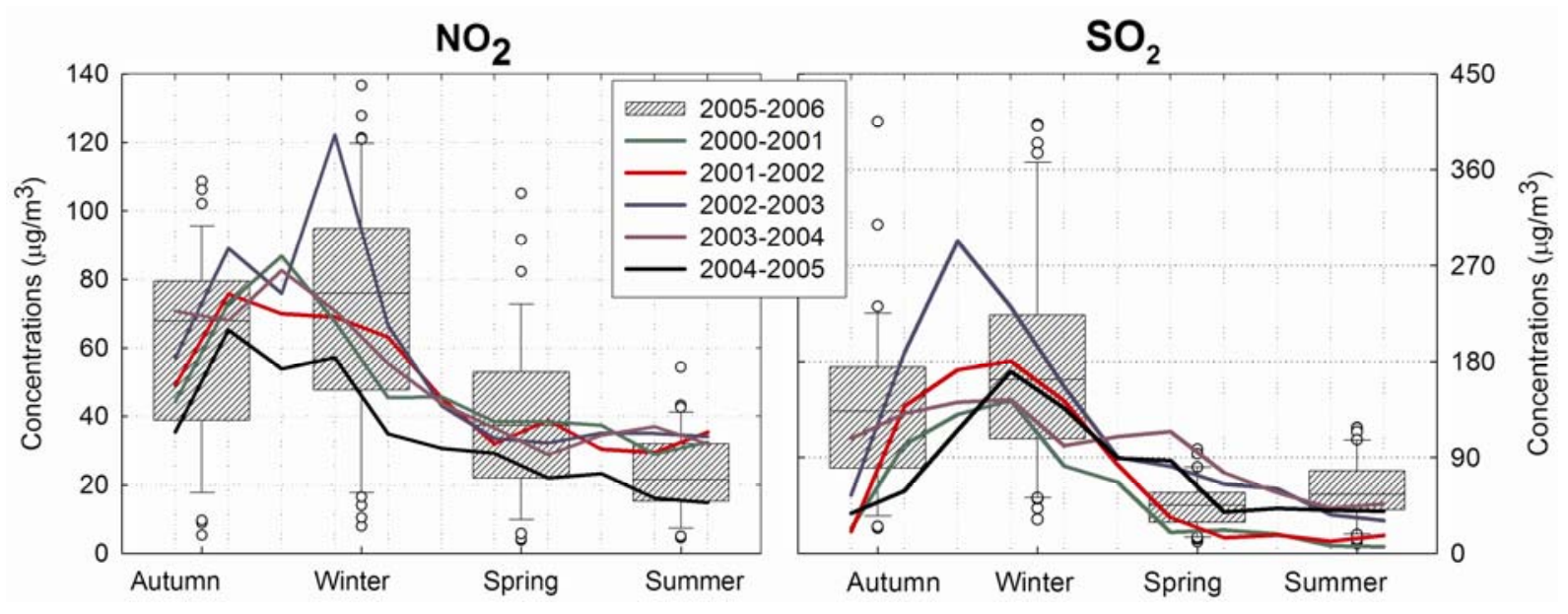

Fig. (3). Box-plot of $\mathrm{NO}_{2}$ and $\mathrm{SO}_{2}$ concentrations calculated among the 40 sites (see Fig. 1), compared with the average of $\mathrm{NO}_{2}$ and $\mathrm{SO}_{2}$ measured from 2000 to 2005 by automatic analysers at the sites 12 and 32 (Fig. 1) from Lanzhou Environmental Monitoring Centre [Lanzhou EPB, 2005].

21, 22]. A number of studies have pointed out that the dynamics of gaseous pollutants in the Lanzhou Valley is considerably influenced by this particular regional meteorology in addition to the natural and anthropogenic emissions [9].

\subsection{Frequency Distributions of Urban Air Pollution}

The results of the normality test, conducted according to section 2, are reported in Table 2. Data normality was tested by excluding the outliers from the total number of observations, in order to have a more significant statistical sample size [15]. With only one exception, all the space-series passed the normality test: the space-dataset matched the pattern expected if the data were drawn from a population with a normal distribution. This might indicate that when the outliers are not included in the analysis and a sufficiently long data averaging time is used, the distribution of the selected gaseous pollutants concentrations among the 40 sites in the urban area of Lanzhou was determined by the diffusion of emission sources in space [15]. This finding might very likely be explained by the distribution of these sources with respect to the sampling locations, and by the particular topography of the measurement area. In fact, due to the particular topography of the Lanzhou Valley (Fig. 1), the surface wind speed is usually very low, and the dominant surface wind direction is from East [9]. This could have favoured the spatial diffusion of emission sources with the sampling points downwind each other. Another determinant factor could have been the one-month integration time used for the measurements: our data do not include short-term (e.g. within minutes) spatial fluctuations - which are very different from spatial fluctuations in monthly averages.

The only exception in the normality behaviour of Benzene FD in spring (Table 1) is somehow interesting. The analysis of the seasonal FDs of its 1-month average spaceseries (Fig. 4) shows that the FD is extremely peaked in spring with a median value $\left(4.5 \mu \mathrm{g} / \mathrm{m}^{3}\right)$ lower than the mean. This indicates a very low spatial variation, with concentrations spatially homogeneous. Only at few sites we found higher concentrations, probably due to their proximity to industrial emission sources. The industrial emission contribution should have increased the difference between the statistic mean and the median (not including the outliers). The different chemical reactivity can probably explain the anomaly found only for Benzene and not for the Xylenes (more reactive). After the emission takes place, the more the pollutant is inert, the more it simply disperses: a concentration gradient with increasing distance to the source develops [18]. If the time is sufficient, concentrations tend to homogenise the more chemically reactive Xylenes should develop a steeper concentration gradient. Junge [23] first and then Brimblecombe [24] established the relationship between the half-life and the spatial coefficient of variation (CV) of several gases on a global scale: for highly reactive species the highest CVs were observed, for inert gases the CVs were the smallest. Also Costabile et al. [5,15] found similar results using a methodology same as the one used in this work.

The analysis of spatial pollutant FDs (Fig. 4) also reveals the particular seasonal behaviour shown by Benzene and Xylenes with autumn values higher than winter ones, contrary to the other pollutants. When compared to Toluene FD, the median values of Benzene and Xylenes in autumn were higher than in winter (Fig. 4). The higher spatial concentration gradients for Xylenes should be likely due to its different chemical reactivity, as discussed above. On the other hand, the $\mathrm{SO}_{2} \mathrm{FD}$ in winter differed from the one in autumn in its bimodality. Interestingly enough, the highest winter mode is found at residential sites, whereas the lower winter FD mode is same as the only mode found in autumn. Conversely, $\mathrm{NO}_{2}$ always shows a double mode, with urban background sites (labelled as $\mathrm{A}$ in the figures) always on the lower mode. The distances between sources and receptors should determine the chemical reactions governing the measured concentrations. Contrary to other pollutants, $\mathrm{NO}_{2}$ (and NO) have time scales of their chemical reactions of the order of tens of seconds [25]. This lower time scale could have produced significant (from a statistical point of view) concentration variations in the urban background locations. This could have induced a second mode in the FD. Finally, it may be interesting to note as the $\mathrm{NO}_{\mathrm{x}} \mathrm{FD}$ in summer seems 

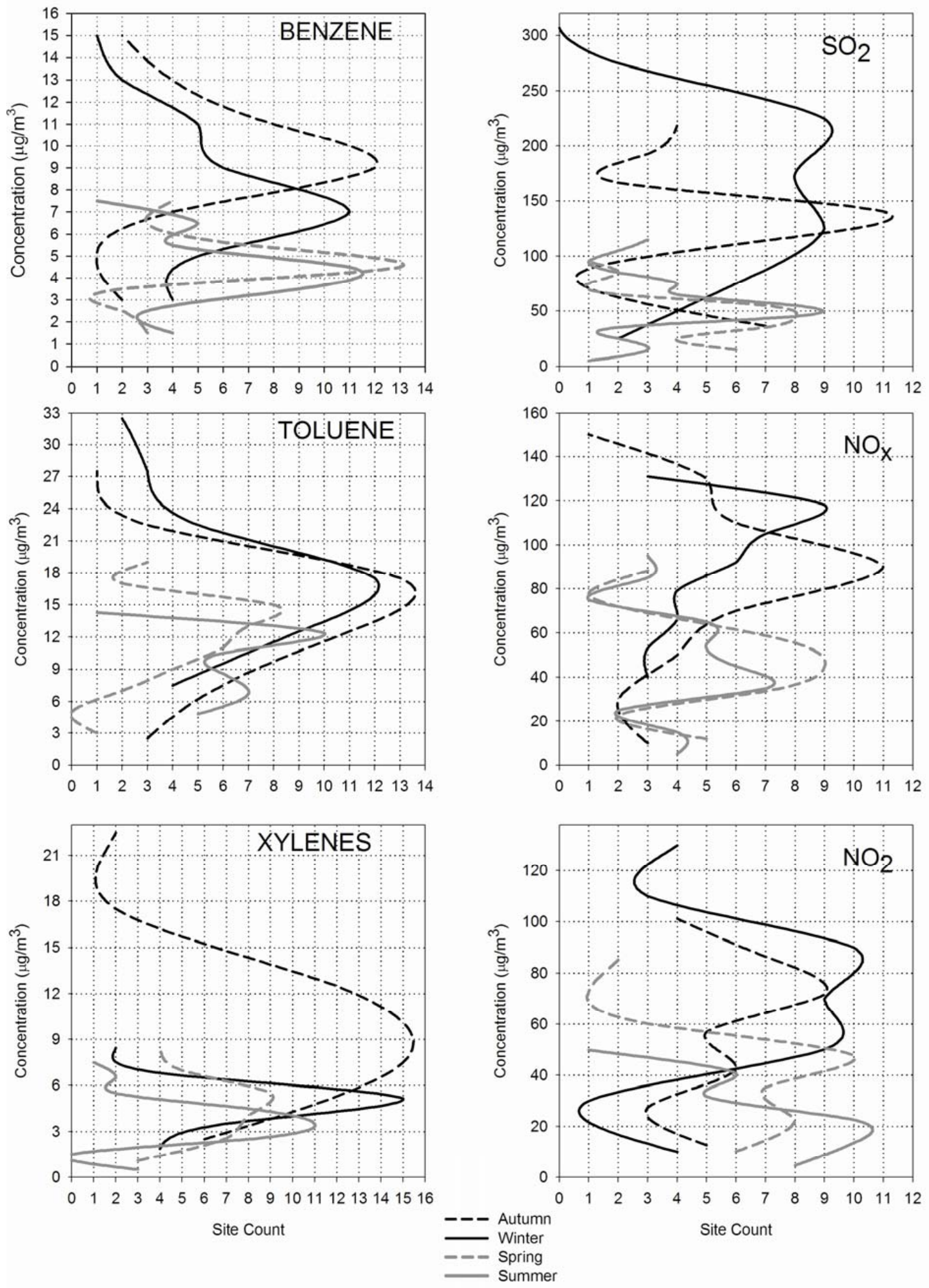

Fig. (4). Frequency distributions in space measured during the four seasonal campaigns for all the pollutants.

to be "included" in its spring FD (Fig. 4). This result suggests that in spring the concentrations were more spatially diffused than in summer.

\subsection{Representativeness of Measurements}

Our findings on the normality of the FD of pollutant concentrations may likely be useful in understanding the dynam- 


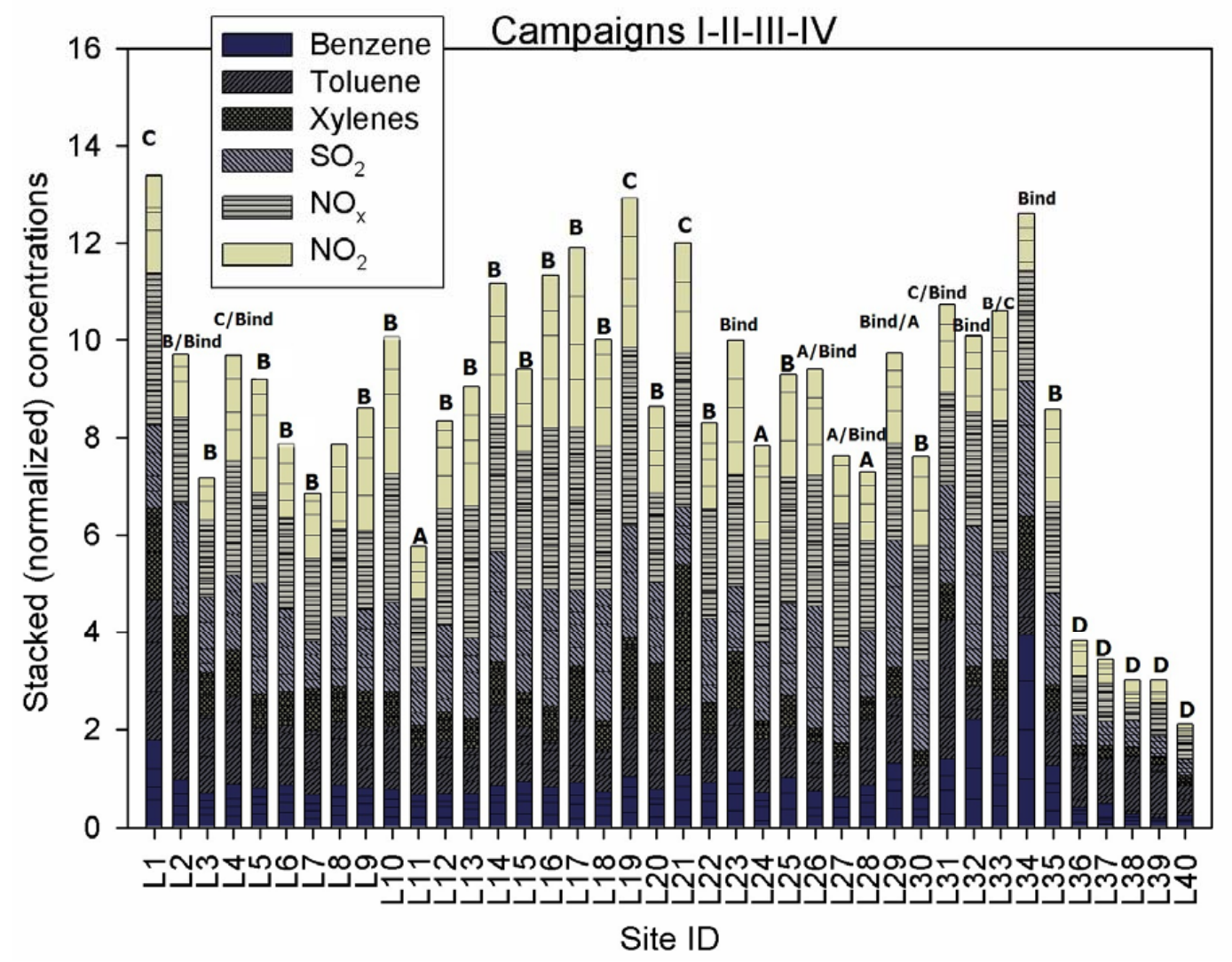

Fig. (5). Air pollutant concentrations at 40 sites (L1,.., L40) standardized between 0 and 1 and stacked at every site with respect to the sampling campaigns and the pollutant species. Each site is classified according to: Type A) urban background station in urban area, Type B) residential zone, Type C) traffic station in urban area, Type Bind) industrial station, Type D) regional background station in suburban/rural area.

ics of the spatial distribution of urban air pollution. For normally distributed pollutants in space the choice of the site where to monitor air quality for health-effects studies might probably be less critical. The very high correlation between concentration levels of pollutants measured at different locations and lying on a normal FD can enhance the identification of homogeneous areas in the city. These areas are representative of homogeneous concentration levels (i.e., regional background, industrial areas) which continuously vary in the city.

A better understanding of measurement representativeness can enhance the process of "network design" according to the European Legislation [26]. To explanatory purpose, Fig. (5) shows air pollutant concentrations at the 40 sites $(\mathrm{L} 1, \ldots, \mathrm{L} 40)$ standardized between 0 and 1 and stacked at every site with respect to the sampling campaigns and the pollutant species. The sites (i) 1,19, (ii) 31,34, and (iii) 16, 17,18 can be considered as representative of the highest concentrations of (i) traffic, (ii) industrial, and (iii) residential areas, respectively. As well, the sites (iv) 36-40, and (v) 11, 24 as representative of air pollution in (iv) regional- and (v) urban- background areas, respectively. When these sites are chosen for setting-up an air quality monitoring system, the resulting network will have stations measuring: (i) the highest pollutant concentrations; (ii) the representative concentra- tions in areas of high population density; (iii) the impact of major pollution emissions sources; (iv) the general background concentration levels. This system could likely better comply with the present regulations (EEA, 1998).

\section{CONCLUSIONS}

The intra-urban distribution of $\mathrm{SO}_{2}, \mathrm{NO}_{\mathrm{x}}, \mathrm{NO}_{2}$, Benzene, Toluene, and Xylenes was investigated in one of the world's most polluted cities, Lanzhou, China. Measurements were carried out for one year (2005-2006) simultaneously at forty locations. The locations were classified according to the proximity to relevant point emission sources, and selected as "representative" of typical homogeneous urban air pollution areas - urban background, traffic, industrial and residential. As a general finding, the selected air pollutant concentrations often exceed the EU limit values, and varied significantly with space, time, and representativeness of measurements.

The space-dataset was found to match the pattern expected if the data was drawn from a population with a normal distribution. This result suggests that the spatial distribution of urban air pollution in Lanzhou can be significantly described in terms of diffusion of emission sources in space, when the measurement averaging time is sufficiently long. This might be important to establish a relationship between air quality measurement representativeness and human expo- 
sure assessment. For normally distributed pollutants in space the assessment of homogeneous areas of air pollution representativeness might be less critical - and consequently, the selection of the sites where to monitor air quality for healtheffects studies. The process of designing an air quality monitoring network compliant with the actual regulations could also be enhanced.

The data-set was necessarily limited by the unavailability of other public health relevant pollutants, such as ozone, $\mathrm{CO}$ and PM. However, the findings of this study have the potential to provide important insight for intra-urban distribution of major air pollutants, and future exposure studies involving pollutants with large spatial variations.

\section{ACKNOWLEDGEMENTS}

The authors would like to thank the Italian Ministry for Environment, Land, and Sea for the funding of this work under the Sino Italian Cooperation Program for environmental protection, and the Environmental Protection Bureau and Environmental Monitoring Centre of Lanzhou for its strong commitment.

\section{REFERENCES}

[1] Briggs DJ. Exposure assessment. In: Elliott P, Wakefield JC, Best NG, Briggs DJ, Eds. Spatial epidemiology: methods and applications. Oxford: Oxford University Press 2000; pp. 335-59.

[2] Monn C. Exposure assessment of air pollutants: a review on spatial heterogeneity and indoor/outdoor/personal exposure to suspended particulate matter, nitrogen dioxide and ozone. Atmos Environ 2001; 35: 1-32.

[3] Jerrett M, Arain A, Kanaroglou P, Beckerman B, Potoglou D, Sahsuvaroglu T. A review and evaluation of intraurban air pollution exposure models. J Expos Anal Environ Epidemiol 2005; 15: 185-204.

[4] Miller KA, Siscovick DS, Sheppard L, et al. Long-term exposure to air pollution and incidence of cardiovascular events in women. $\mathrm{N}$ Engl J Med 2007; 356: 447-58.

[5] Costabile F, De Santis F, Wang F, Hong W, Liu F, Allegrini I. Representativeness of urban highest polluted zones for sitting traffic-oriented air monitoring stations in a Chinese city. JSME Int J B 2006b; 49: 35-41.

[6] Kimmel V, Kaasik M. Assessment of urban air quality in South Estonia by simple measures. Environ Modell Assess 2003; 8: 4753.

[7] Fagundez A, Fernandez VL, Marino TH, et al. Preliminary air pollution monitoring in San Miguel, Buenos Aires. Environ Monit Assess 2001; 71: 61-70.
[8] Xia DS, Chen FH, Bloemendal J, Liu XM, Yu Y, Yang LP. Magnetic properties of urban dustfall in Lanzhou, China, and its environmental implications. Atmos Environ 2008; 42: 2198-207.

[9] Ta W, Wang T, Xiao H, Zhu X, Xiao Z. Gaseous and particulate air pollution in the Lanzhou Valley, China. Sci Total Environ 2004; 320: $163-76$.

[10] Qi B, Wang JF, Wang H. Characteristics of air pollution and its cause in Lanzhou city. Shaxi Meteorol 2001; 6: 18-20.

[11] Xu H, Zhai J, Liu ZQ. Study on current situation of atmospheric pollution of Lanzhou and the countermeasures. Environ Protect Sci 2003; 29: 4-6.

[12] Wang X. The current situation of environmental quality and the countermeasures in Lanzhou. Gansu Sci Technol 2005; 21: 8-11

[13] Bertoni G, Tappa R, Allegrini I. The internal consistency of the Analyst diffusive sampler - a long term field test. Chromatographia 2000; 54: 653-7.

[14] De Santis F, Dogeroglu T, Fino A, Menichelli S, Vazzana C, Allegrini I. Laboratory development and field evaluation of a new diffusive sampler to collect nitrogen oxides in the ambient air. J Anal Bioanal Chem 2002; 373: 901-7.

[15] Costabile F, Bertoni G, De Santis F, et al. A preliminary assessment of major air pollutants in the city of Suzhou, China. Atmos Environ 2006; 40: 6380-95.

[16] Buccianti A, Rosso F, Vlacci F. Metodi matematici e statistici nelle scienze della terra. Liguori: Naples 2003; Vol. 3.

[17] Lanzhou EPB, Costabile F. Personal communication 2005.

[18] Seinfeld JH. Atmospheric chemistry and physics of air pollution. New York: John Wiley \& Sons 1986.

[19] Council Directive 30/99 EC of 22nd April 1999 relating to limit values for sulphur dioxide, nitrogen dioxide and oxides of nitrogen, particulate matter and lead in ambient air. Off J L163, 29/06/1999, 41-60.

[20] Wang S, Wei Y, Shang K. The impacts of different kinds of dust events on PM10 pollution in northern China. Atmos Environ 2006; 40: 7975-82.

[21] Wei F, Teng E, Wu G, et al. Ambient concentrations and elemental compositions of PM10 and PM2.5 in four Chinese cities. Environ Sci Technol 1999; 33: 4188-93.

[22] Hu YQ, Ge Z, Liu J, Zhang Y, Wei G. An observational experiment of surface layer over Lanzhou mountainous region in the early winter. Chin J Atmos Sci 1988; 13: 465-75.

[23] Junge CE. Residence time and variability of tropospheric trace gases. Tellus 1974; 26: 477-88.

[24] Brimblecombe P. Air composition and chemistry. Cambridge: Cambridge University Press 1986; p. 38.

[25] Palmgren F, Berkowicz R, Hertel O, Vignati E. Effects of reduction in NOx on the NO2 levels in urban streets. Sci Total Environ 1996 189/190: 409-15.

[26] European Environmental Agency; Van Aalst R, Edwards L, Pulles T, De Saeger E, Tombrou M, Tønnesen D. Guidance report on preliminary assessment under EC air quality directives. Project Manager: Kielland G, Copenhagen 1998

\begin{tabular}{lll}
\hline Received: July 23, 2009 & Revised: December 10, 2009 Accepted: January 07, 2010
\end{tabular}

(c) Costabile et al.; Licensee Bentham Open.

This is an open access article licensed under the terms of the Creative Commons Attribution Non-Commercial License (http://creativecommons.org/licenses/by-nc/3.0/) which permits unrestricted, non-commercial use, distribution and reproduction in any medium, provided the work is properly cited. 